\title{
Carotid artery stenting versus endarterectomy for the treatment of both symptomatic and asymptomatic patients with carotid artery stenosis: 2 years' experience in a high-volume center
}

\author{
Dariusz Janczak ${ }^{1, A, E}$, Maciej Malinowski, ${ }^{1, A, E}$, Agnieszka Ziomek ${ }^{1, B, C}$, Jakub Kobecki ${ }^{2, B, D}$, Michał Leśniak ${ }^{1, B, D}$, \\ Tadeusz Dorobisz ${ }^{3, A, B}$, Karolina Dorobisz ${ }^{4, B, D}$, Dawid Janczak ${ }^{3, B, C}$, Mariusz Chabowski ${ }^{1,2, C, D}$ \\ ${ }^{1}$ Division of Surgical Procedures, Department of Clinical Nursing, Faculty of Health Sciences, Wroclaw Medical University, Poland \\ ${ }^{2}$ Department of Surgery, $4^{\text {th }}$ Military Teaching Hospital, Wrocław, Poland \\ ${ }^{3}$ Division of Oncology and Palliative Care, Faculty of Health Sciences, Wroclaw Medical University, Poland \\ ${ }^{4}$ Department of Otolaryngology, Head and Neck Surgery, Faculty of Postgraduate Medical Training, Wroclaw Medical University, Poland \\ A - research concept and design; $\mathrm{B}$ - collection and/or assembly of data; $\mathrm{C}$ - data analysis and interpretation; \\ $\mathrm{D}$ - writing the article; $\mathrm{E}$ - critical revision of the article; $\mathrm{F}$ - final approval of the article
}

\section{Address for correspondence}

Mariusz Chabowski

E-mail: mailto:mariusz.chabowski@gmail.com

Funding sources

None declared

Conflict of interest

None declared

Received on March 23, 2017

Reviewed on May 16, 2017

Accepted on July 14, 2017

\begin{abstract}
Background. Carotid endarterectomy (CEA) and carotid artery stenting (CAS) are the 2 current standard treatments for carotid artery stenosis. There is still no well-defined consensus with regard to their superiority. However, the minimally invasive nature of endovascular treatment makes CAS increasingly popular among vascular surgeons.
\end{abstract}

Objectives. The aim of the study is to compare the safety and efficacy of CEA and CAS in patients with symptomatic and asymptomatic carotid artery stenosis.

Material and methods. A single-center, retrospective analysis of patients who were treated for carotid artery stenosis using CAS or CEA between January 2014 and December 2015 was carried out. There were 471 patients (266 CEA and 205 CAS) who were eligible for inclusion. The vast majority of the patients had significant (>70\%) stenosis of the internal carotid artery (92.1\% of CEA and $87.8 \%$ of CAS). The occlusion of the contralateral carotid artery was observed in $9.8 \%$ of all cases (2.6\% of CEA vs $17.7 \%$ of CAS).

Results. The occurrence of complications, such as stroke, myocardial infarction (MI) and death, did not vary statistically between the groups. There were 9 events of stroke in the CEA group (3.4\%) and 8 in the CAS group (3.9\%), 3 of which were fatal. There were no significant differences between the 2 groups $\left(x^{2}=0.76\right.$; $p>0.05$ ). There was no higher risk of mortality in any group (Fisher's exact test; $p=0.08$ ). Symptomatic patients had a higher incidence of stroke than asymptomatic patients across both groups $\left(x^{2}=6.36 ; p<0.05\right.$; hazard ratio $3.03(1.26-7.33))$.

Conclusions. Carotid endarterectomy is equally effective as CAS in stroke prevention, but is associated with a higher incidence of cranial nerve palsy, access site hematoma and other non-stroke complications. Symptomatic patients had a higher incidence of stroke, regardless of the treatment method.

Key words: carotid artery stenting, carotid endarterectomy, carotid artery stenosis

DOI

10.17219/acem/75902

Copyright

Copyright by Author(s)

This is an article distributed under the terms of the

Creative Commons Attribution Non-Commercial License

(http://creativecommons.org/licenses/by-nc-nd/4.0/) 


\section{Introduction}

Stroke is a major cause of disability in elderly patients and is the $3^{\text {rd }}$ most common cause of death in developed countries. Approximately 75-80\% of all strokes are of ischemic etiology, and $20 \%$ of ischemic strokes are secondary to extracranial cerebrovascular disease. ${ }^{1}$ Atherosclerosis is responsible for carotid artery stenosis in more than $90 \%$ of patients. Endarterectomy of the carotid artery (CEA) was the gold standard for treatment of carotid artery stenosis until the introduction of carotid artery stenting (CAS) in the 1980s. Despite numerous multicenter, randomized clinical trials, it still remains unclear which of the 2 methods is superior. The aim of this study was to assess the efficacy and safety of CAS vs CEA in patients with symptomatic and asymptomatic carotid artery stenosis.

\section{Material and methods}

This is a single-center, retrospective study of patients treated for carotid artery stenosis in the Department of Vascular Surgery, $4^{\text {th }}$ Military Teaching Hospital in Wrocław (Poland) between January 2014 and December 2015. Symptomatic patients were eligible for inclusion if there was 50-99\% carotid artery stenosis, while asymptomatic patients were eligible if there was 70-99\% carotid artery stenosis. Carotid stenosis is considered symptomatic when patients experienced a stroke, a transient ischemic attack (TIA) or amaurosis fugax in the last 6 months. Patients with a carotid artery aneurysm or carotid artery dissection were excluded from this study. For the assessment of carotid artery stenosis, each patient underwent duplex ultrasound examination prior to CAS or CEA. Patients were allocated to the study groups by the surgeon. There was no randomization since it was a case-control study. Directly before the procedure (both CAS and CEA), each patient was administered intravenously $16 \mathrm{mg}$ of dexamethason, $40 \mathrm{mg}$ of pantoprazol, $12 \mathrm{~g}$ of piracetam, and $10 \mathrm{mg}$ of vinpocetine. Each patient was provided with 24-hour medical supervision after the procedure.

All patients provided written informed consent to having their data included in this study. This study was approved by the Medical University of Lodz Ethics Committee (No. 204/2015). All procedures performed in studies involving human participants were in accordance with the ethical standards of the institutional and/or national research committee and with the 1964 Helsinki declaration and its later amendments or comparable ethical standards.

\section{Carotid artery stenting}

Every CAS procedure was performed by an experienced vascular surgeon, i.e., one who performs approx. 100 such procedures yearly. Each patient was given dual antiplatelet therapy the day before the procedure (clopidogrel and aspirin, except for patients with contraindications). Additionally, an intravenous injection of 5,000 UI of unfractionated heparin was performed several minutes before stent implantation and low-molecular-weight heparin was administered in therapeutic doses for at least $24 \mathrm{~h}$ postoperatively. The common femoral artery access was used in all the procedures. Abbot Xact $^{\circledR}$ (Abbott Laboratories, Lake Bluff, USA) and Boston Scientific Carotid Wallstent ${ }^{\circledR}$ (Boston Scientific, Marlborough, USA) were the stents used. Abbott Emboshield NAVA $^{\circledR}$ (Abbott Vascular, Lake Bluff, USA) and Boston Scientific Filter Wire ${ }^{\circledR}$ (Boston Scientific, Marlborough, USA) were the distal neuroprotection devices used. Pre- and postdilatation were performed when needed. In the case of bradycardia, atropine was given intravenously. Dual antiplatelet therapy was continued for 3 months unless contraindicated.

\section{Carotid endarterectomy}

The surgeries were performed under local anesthesia. The surgical technique (patch, shunt or suture) was chosen by the operating surgeon. Directly before carotid artery clamping, a 5,000 UI infusion of unfractionated heparin was administered.

\section{Statistical analysis}

Data analysis was performed using IBM SPSS v. 23.00 for Macintosh (IBM, Armonk, USA). Quantitative data, presented as mean values and standard deviations, was compared using a t-test. A $\chi^{2}$ test was used to analyze nominal variables. The strength of the relationship between variables was calculated with the mean square contingency coefficient and the assessment of relative risk. Pearson's product - moment correlation coefficient was used to analyze correlations. Statistical test results were recognized as significant when the p-value was $<0.05$.

\section{Endpoints}

Patients were evaluated for perioperative stroke, death and myocardial infarction (MI) during 7 days of postoperative follow-up. Stroke was defined as a sudden deterioration in neurological condition, lasting for at least $24 \mathrm{~h}$ and confirmed by a cranial computer tomography (CT) scan. Severe stroke was defined as a stroke that led to death within $72 \mathrm{~h}$ of occurrence, or when the score in the modified Rankin scale was 3 points or more. Myocardial infarction diagnosis was based on clinical symptoms, the dynamic elevation of troponin levels and electrocardiography (ECG) changes.

\section{Results}

Four hundred seventy-one patients with internal carotid artery (ICA) stenosis were eligible for analysis. Two hundred sixty-six of them underwent classic CEA and 205 of them underwent CAS. Age was similar in both 
groups $(69.9 \pm 8.8$ years in the CEA group vs $68.7 \pm 9.6$ years in the CAS group; $\mathrm{p}>0.05)$. There were slightly more male patients in the CAS group (52.2\% males in CEA vs $61.4 \%$ males in CAS; $\mathrm{p}<0.05$ ). Elderly patients (>80 years old) constituted $16.9 \%$ of the CEA group and $17.1 \%$ of the CAS group. The vast majority of patients had significant $(>70 \%)$ stenosis of the internal carotid artery (92.1\% of CEA and $87.8 \%$ of CAS). The occlusion of the contralateral carotid artery was observed in $9.8 \%$ of all cases $(2.6 \%$ of CEA vs $17.7 \%$ of CAS). Diabetes was more prevalent in the endovascular stenting group (29.3\% of CAS vs $23.3 \%$ of CEA), while dyslipidemia was more frequent in the endarterectomy group. Other risk factors for cardiovascular diseases were distributed similarly in both groups (Table 1). A distal neuroprotective device was used in $96.6 \%$ of patients in the CAS group. Table 2 shows the number of complications during 7 days of postoperative follow-up. The occurrence of complications, such as stroke, MI and death, did not vary statistically between the groups. We observed such complications in 8 patients (3.9\%) after CAS and in 9 patients $(3.4 \%)$ after CEA (Fisher's exact test; $\mathrm{p}=0.08)$. Nine strokes

Table 1. Baseline characteristics of the study population

\begin{tabular}{|l|l|l|}
\multicolumn{1}{|c|}{ Characteristic } & \multicolumn{1}{|c|}{$\begin{array}{c}\text { CEA } \\
(n=266)\end{array}$} & $\begin{array}{c}\text { CAS } \\
(n=205)\end{array}$ \\
\hline Age [years] & $69.9 \pm 8.8$ & $68.7 \pm 9.6$ \\
Male sex [\%] & 52.2 & 61.4 \\
\hline Diabetes mellitus [\%] & 23.3 & 29.3 \\
\hline Dyslipidemia [\%] & 18.2 & 19.1 \\
\hline ICA stenosis & & \\
$<70 \%$ & 5.6 & 12.2 \\
$\geq 70 \%$ & 92.1 & 87.8 \\
\hline kinking & 2.3 & \\
\hline Occlusion of the contralateral ICA [\%] & 2.6 & 17.7 \\
\hline Symptomatic patients [\%] & 39.5 & 29.3 \\
\hline Treatment technique [\%] & & \\
continuous stitch & 86.1 & - \\
vascular patch & 13.9 & - \\
eversion \\
shunt
\end{tabular}

CEA - carotid endarterectomy; CAS - carotid artery stenting; ICA - internal carotid stenosis.

Table 2. Complications during 7 days of postoperative follow-up

\begin{tabular}{l|c|c|c|c|}
\multirow{2}{*}{$\begin{array}{l}\text { Perioperative } \\
\text { complications }\end{array}$} & \multicolumn{3}{|c|}{ CEA } & \multicolumn{2}{c|}{ CAS } \\
\cline { 2 - 5 } & $\begin{array}{c}\text { total CEA } \\
(n=266)\end{array}$ & $\begin{array}{c}\text { symptomatic } \\
\text { patients } \\
(n=105)\end{array}$ & $\begin{array}{c}\text { total CAS } \\
(n=205)\end{array}$ & $\begin{array}{c}\text { symptomatic } \\
\text { patients } \\
(n=60)\end{array}$ \\
\hline Death & 0 & 0 & $3(1.5 \%)$ & 0 \\
\hline Stroke & $9(3.4 \%)$ & $5(4.8 \%)$ & $5(2.4 \%)$ & $2(3.3 \%)$ \\
\hline Ml & 0 & 0 & 0 & 0 \\
\hline Total & $9(3.4 \%)$ & $5(4.8 \%)$ & $8(3.9 \%)$ & $2(3.3 \%)$ \\
\hline
\end{tabular}

CEA - carotid endarterectomy; CAS - carotid artery stenting; Ml - myocardial infarction. were observed in the CEA group, 8 of which were of ischemic etiology and 1 was caused by a intracerebral hematoma. In the CAS group, 3 out of 8 strokes that occurred were fatal. Myocardial infarction did not occur in any patient. This data did not lead to the conclusion that there was a higher risk of mortality in any group (Fisher's exact test; $\mathrm{p}=0.08$ ).

\section{Symptomatic vs asymptomatic patients}

The study showed a statistically significantly higher incidence of perioperative complications in symptomatic patients $\left(x^{2}=6.36 ; p<0.05\right)$. The evaluation of the relative risk (symptomatic patients vs asymptomatic ones) of stroke during the perioperative period was 3.03 (1.26-7.33). The occurrence of other complications, such as death or MI, did not differ between the 2 groups. The study did not reveal a correlation between age and the carotid artery stenosis percentage $(r=-0.79 ; \mathrm{p}>0.05)$ or between age and the incidence of endpoint.

Table 3 shows additional adverse events. They occurred more frequently in the CEA group than in the CAS group $(14.6 \%$ vs $4.39 \%$; $\mathrm{p}<0.05)$. In the CEA group, 12 patients $(4.5 \%)$ required reoperation because of a hematoma at the site of the incision. One case of hematoma turned out to be a pseudoaneurysm due to the unsealing of the arteriotomy suture, which led to ischemic stroke. Wound infections, pulmonary edema and the inferior branch retinal artery embolism were complications observed exclusively in CEA patients.

The small number of additional complications among patients that underwent endovascular treatment is noteworthy. Only 3 (1.4\%) out of 205 patients in the CAS group required surgery due to a pseudoaneurysm after puncturing the common femoral artery (AFC).

Perioperative transient central nervous system ischemia symptoms occurred in both groups with a comparable frequency during the procedure (4.1\% CEA vs 5.4\% CAS) and in the first $24 \mathrm{~h}$ after the surgery (3.0\% CEA vs $2.4 \% \mathrm{CAS}$ ).

\section{Discussion}

Stroke prevention is the main purpose of the treatment of carotid artery stenosis. Despite numerous papers from recent randomized studies comparing CAS and CEA, including the International Carotid Stenting Study (ICSS), Carotid Revascularization Endarterectomy vs Stenting Trial (CREST) and Carotid and Vertebral Artery Transluminal Angioplasty Study (CAVATAS), it still remains unclear which of the 2 methods is superior.

One of the first major clinical trials comparing CAS and CEA was the Endarterectomy vs Angioplasty in Patients with Symptomatic Severe Carotid Stenosis (EVA-3S) trial. They found that the cumulative 4-year risk 
Table 3. Additional adverse events

\begin{tabular}{|l|l|l|}
\hline \multicolumn{1}{|c|}{ Perioperative complications (continued) } & CAS & CEA \\
\hline Laryngeal nerve palsy & 0 & $3(1.13 \%)$ \\
\hline Pharyngeal and laryngeal hematoma & 0 & $3(1.13 \%)$ \\
\hline Arytenoid cartilage edema & 0 & $1(0.38 \%)$ \\
\hline Paralysis of the marginal mandibular branch of the facial nerve & 0 & $1(0.75 \%)$ \\
\hline Reinke's edema & 0 & $12(4.5 \%)$ \\
\hline Reoperations due to & & 0 \\
\hline $\begin{array}{l}\text { hematoma in the site of incision } \\
\text { Pseudoaneurysm }\end{array}$ & 0 & $3(1.13 \%)$ \\
\hline Wound infection & $3(1.47 \%)$ & $1(0.38 \%)$ \\
\hline Pulmonary edema & 0 & $1(0.38 \%)$ \\
\hline Epilepsy after local anesthetic & 0 & $1(0.38 \%)$ \\
\hline Postoperative TIA & 0 & $8(3 \%)$ \\
\hline Postoperative psychotic symptoms requiring drug administration & $1(0.49 \%)$ & $3(1.13 \%)$ \\
\hline Total & 9 & $3(4.39 \%)$ \\
\hline
\end{tabular}

CAS - carotid artery stenting; CEA - carotid endarterectomy; ICA - internal carotid stenosis; TIA - transient ischemic attack.

of fatal or disabling stroke did not differ significantly between the CAS and CEA groups (6.3\% vs 4\%). ${ }^{1}$ The CREST showed that the safety and efficacy of CAS and CEA were similar among patients with symptomatic and asymptomatic carotid artery stenosis. The CREST indicated that the risk of stroke, $\mathrm{MI}$ and death is similar in these 2 groups (5.2\% CEA vs 4.5\% CAS). However, it demonstrated a higher periprocedural risk of stroke and death after a CAS procedure. ${ }^{2-4}$ The ICSS results published in "Lancet" in February 2015 did not provide a definitive answer to the question of superiority, either. The primary endpoint was fatal or disabling stroke in any territory. According to the ICSS, stenting is as effective as endarterectomy in the prevention of fatal or disabling stroke $(6.4 \%$ vs $6.5 \%$, respectively). In the ICSS and in the CREST, carotid artery stenting was associated with a higher procedure-related and long-term risk of non-disabling stroke, but the neurological outcomes were not different.,

Our study does not prove the superiority of CAS over CEA, either, though the number of complications is lower. We might relate this to the high number of procedures performed, the frequent application of neuroprotection devices (96.6\%) and the extensive experience of the surgeons. ${ }^{6}$

Due to constant technological progress, the results of the trials published may not be accurate today. In these studies, some of the patients in the endovascular group were treated without stent placement, and embolic protection devices were not available. ${ }^{7}$ These factors might have a significant impact on the number of procedurerelated complications. The availability of new, improved proximal and distal neuroprotection devices and new mesh-covered stents may reduce the number of disabling strokes. ${ }^{8}$
However, a substudy of the ICSS showed that patients who underwent CAS had new ischemic brain lesions about 3 times more often than patients after CEA and, surprisingly, they were more frequent when cerebral protection devices were used. ${ }^{9}$

The incidence of neurological complications in our department is within the target of $<6 \%$ for symptomatic artery sclerosis set by the American Heart Association/American Stroke Association guidelines and $<3 \%$ for asymptomatic patients set by the Therapeutics and Technology Assessment Subcommittee of the American Academy of Neurology. ${ }^{10}$

Our study failed to show a correlation between patients' age and the risk of post-procedural neurological complications. On the contrary, the ICSS, the CREST and the Stent-Protected Angioplasty vs Carotid Endarterectomy (SPACE) trial proved that CAS is associated with better outcomes when performed on younger patients, while CEA is better in older patients. The cut-off point was the age of 70 years. ${ }^{2,4,11}$ This is thought to be caused by increased vasa tortuosity and more calcified atherosclerotic plaques in elderly patients. ${ }^{12,13}$

\section{Limitations of the study}

The patients should preferably be observed for 30 days, but in our study they were followed-up for only 7 days after surgery, so restenosis and delayed neurological events were omitted. Our study is retrospective and represents only a single institution's experience with a small number of patients. There was no randomization, so the results may be influenced by the tendency of operators to surgically treat more sick patients.

\section{Conclusions}

Our analysis showed that CEA is as effective as CAS in stroke prevention, but is associated with a higher incidence of cranial nerve palsy, access site hematoma and other non-stroke complications. Symptomatic patients had a higher incidence of stroke, regardless of the treatment method. A new multi-center, randomized trial with methodology carefully determined by advocates of both CAS and CEA should be conducted in order to provide a final conclusion for this long-lasting dispute on which method is better. 


\section{References}

1. Mas JL, Trinquart L, Leys D, et al. Endarterectomy Versus Angioplasty in Patients with Symptomatic Severe Carotid Stenosis (EVA-3S) trial: Results up to 4 years from a randomised, multicentre trial. Lancet Neurol. 2008;7(10):885-892.

2. Brott TG, Hobson RW, Howard G, et al. Stenting vs endarterectomy for treatment of carotid-artery stenosis. NEngl J Med. 2010;363(1):11-23.

3. Mantese VA, Timaran CH, Chiu D, Begg RJ, Brott TG. The Carotid Revascularization Endarterectomy vs Stenting Trial (CREST): Stenting versus carotid endarterectomy for carotid disease. Stroke. 2010;41(Suppl 10):31-34.

4. Voeks JH, Howard G, Roubin GS, et al. Age and outcomes after carotid stenting and endarterectomy: The carotid revascularization endarterectomy vs stenting trial. Stroke. 2011;42(12):3484-3490.

5. Timaran $\mathrm{CH}$, Mantese VA, Malas $\mathrm{M}$, et al. Differential outcomes of carotid stenting and endarterectomy performed exclusively by vascular surgeons in the Carotid Revascularization Endarterectomy versus Stenting Trial (CREST). J Vasc Surg. 2013;57(2):303-308.

6. Bonati $\mathrm{LH}$, Dobson J, Featherstone RL, et al. Long-term outcomes after stenting versus endarterectomy for treatment of symptomatic carotid stenosis: The International Carotid Stenting Study (ICSS) randomised trial. Lancet. 2015;385(9967):529-538.

7. Endovascular versus surgical treatment in patients with carotid stenosis in the Carotid and Vertebral Artery Transluminal Angioplasty Study (CAVATAS): A randomised trial. Lancet. 2001;357(9270):1729-1737.
8. Schofer J, Musiałek P, Bijuklic K, et al. A prospective, multicenter study of a novel mesh-covered carotid stent: The CGuard CARENET Trial (Carotid Embolic Protection Using MicroNet). JACC CardiovasC Interv. 2015;8(9):1229-1234.

9. Bonati LH, Jongen LM, Haller S, et al. New ischaemic brain lesions on MRI after stenting or endarterectomy for symptomatic carotid stenosis: A substudy of the International Carotid Stenting Study (ICSS). Lancet Neurol. 2010;9(4):353-362.

10. Kernan WN, Ovbiagele B, Black HR, et al. Guidelines for the prevention of stroke in patients with stroke and transient ischemic attack: A guideline for healthcare professionals from the American Heart Association/ American Stroke Association. Stroke. 2014;45(7):2160-2236.

11. Ederle J, Dobson J, Featherstone RL, et al. Carotid artery stenting compared with endarterectomy in patients with symptomatic carotid stenosis (International Carotid Stenting Study): An interim analysis of a randomised controlled trial. Lancet. 2010;375(9719):985-997.

12. Chaturvedi S, Bruno A, Feasby T, et al. Carotid endarterectomy an evidence-based review: Report of the Therapeutics and Technology Assessment Subcommittee of the American Academy of Neurology. Neurology. 2005;65(6):794-801.

13. Bradac O, Mohapl M, Kramar F, et al. Carotid endarterectomy and carotid artery stenting: Changing paradigm during ten years in a high-volume centre. Acta Neurochir(Wien). 2014;156(9):1705-1712. 